\title{
Construcción de un componente que permita manipular un gráfico para su almacenamiento como texto en una base de datos
}

\author{
Construction of a component that allows to manipulate a graph \\ for their storage like text in a database
}

Antonio Nathaniel Neyra Zapana*

http://dx.doi.org/10.21503/CienciayDesarrollo.2010.v11.06

\section{RESUMEN}

El presente trabajo trata de la manipulación de un gráfico al almacenarlo en una base de datos, lo cual creará un componente (librería) capaz de convertir dicho gráfico en una cadena de caracteres, y luego se procederá almacenar en un campo, texto de la base de datos, con el propósito de reducir espacio.

Este componente (librería) será capaz de agregarse a cualquier aplicación que se desee; tiene la flexibilidad de trabajar con diferentes bases de datos, así como también en diferentes formularios; solo tiene que haber un campo texto en donde se almacene la imagen o gráfico.

Palabras clave: componente o librería, base de datos, campo texto, gráfico o imagen, almacenamiento.

\section{ABSTRACT}

This paper deals with the manipulation of a graphic when stored in a database, which created a component (library) capable of making this graphic in a string and then proceed stored in a text field data base, in order to reduce space.

This component (library) will be able to add any application you want, you have the flexibility to work with different databases, as well as in different forms, and one has to be a text field where you store the image or graphic.

Key words: component or library, database, text field, graphic or image, storage.

\section{INTRODUCCIÓN}

El presente trabajo está destinado a la creación de otro método de almacenamiento de imágenes en una Base de Datos, tratando de solucionar las desventajas que actualmente se dan.

Las razones por las que se decidió por este trabajo son: la importancia que lleva hoy por hoy, tener una base de datos segura, confiable y de menor peso, en donde se pueda contar con datos, imágenes, vídeos, audios, etc.; es decir, una base de datos multimedia.

Para lograr este objetivo se ve la necesidad de convertir dichas imágenes en una trama de texto, la cual se almacenará en la base de batos, logrando así que no ocupe mucho espacio y, que el espacio físico que ocupa, sea en la misma base de datos, para mayor seguridad. Y también se podrá convertir en forma inversa para usarla en alguna aplicación cualquiera.

\footnotetext{
* Alumno de la Escuela Académico-Profesional de Ingeniería de Sistemas e Informática, Filial Arequipa.
} 


\section{Problema de la investigación}

El problema principal de la investigación es el de resolver las desventajas que encontramos en las dos formas de almacenamiento de imágenes. Primera forma: solo almacenar la ruta donde se encuentran las imágenes (seguridad). Segunda forma: almacenar las imágenes dentro de la base de datos (peso).

\section{Objetivo de la investigación}

Construir un componente que permita manipular un gráfico, para su almacenamiento como texto en una base de datos, así como su recuperación y presentación.

\section{Justificación e importancia}

Actualmente se cuenta con bases de datos multimedia, donde se guardan directamente las imágenes dentro de esta; pero este procedimiento ocupa mucho espacio dentro de la base de datos, lo cual conlleva al problema de sobrepeso. Por otro lado, si se almacena solo la ruta de la imagen, conlleva al problema de seguridad (si se cambian las imágenes a otra carpeta). Para solucionar este problema, se va a proceder a la conversión de dichas imágenes en formato de texto, para que no ocupe mucho espacio y sea más seguro almacenándolas dentro de la base de datos.

La importancia de este proyecto radica en que se tendrá otra forma de almacenamiento de las imágenes en la base de datos, logrando de esta manera, reducir el peso de las imágenes y tener más seguridad de las mismas.

\section{MATERIAL Y MÉTODO}

\section{Descripción de la solución}

En la Figura 1 se esquematiza el proceso que se realiza una vez instalado el componente en una aplicación.

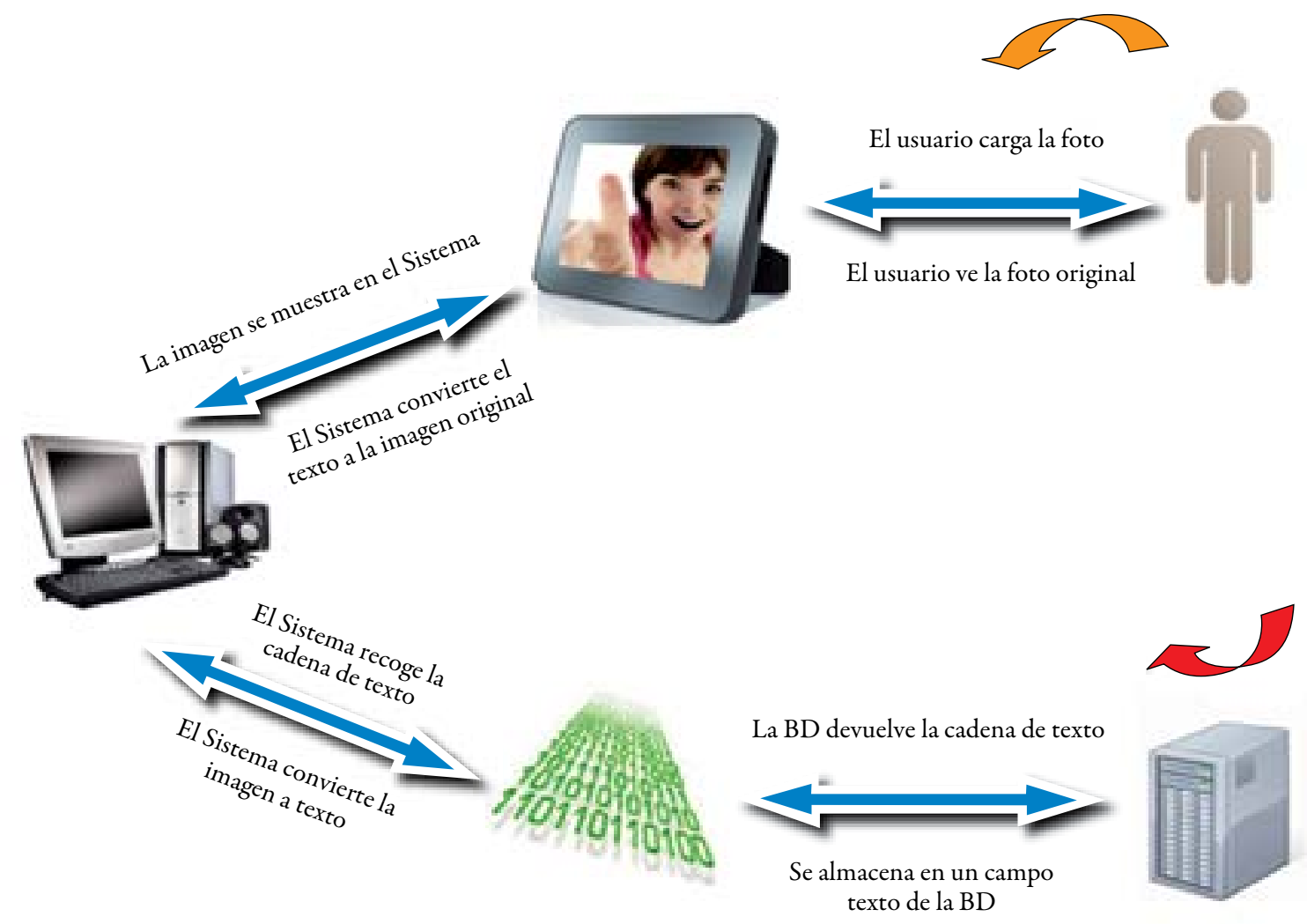

Figura 1 
Los requisitos funcionales del componente se muestran a continuación.

\begin{tabular}{c|c}
\hline CÓDIGO & REQUERIMIENTOS \\
\hline RF-001 & Tiempo de lectura \\
\hline RF-002 & Peso de la imagen original \\
\hline RF-003 & Peso de la imagen convertida \\
\hline RF-004 & Tiempo de conversión \\
\hline RF-005 & Calidad de la imagen convertida \\
\hline
\end{tabular}

En el diagrama de caso de uso (ver Figura 2) se muestra cómo el componente realiza las siguientes acciones:

- Convertir la imagen a texto

- Convertir el texto a imagen

- Ajustar el tamaño de la imagen.

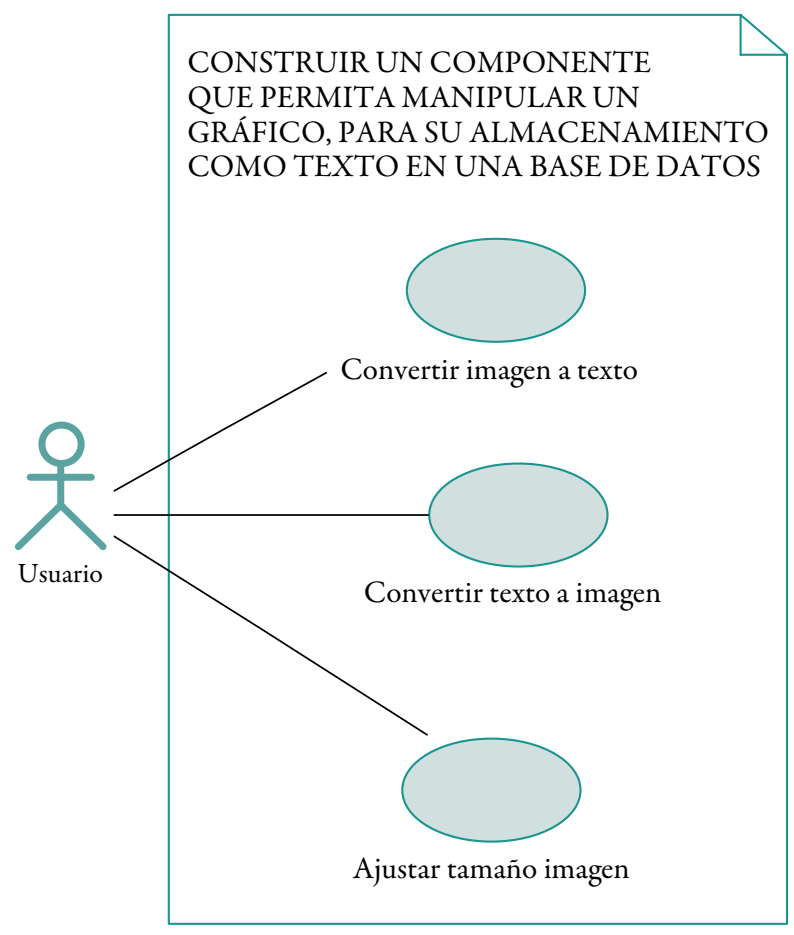

Figura 2

Los diagramas de secuencia (ver Figura 3) muestran las acciones internas del componente; es decir, cómo trabaja el componente para lograr su propósito de conversión.
El primero muestra la conversión de imagen a caracteres, y el segundo muestra la conversión de caracteres a la imagen original.

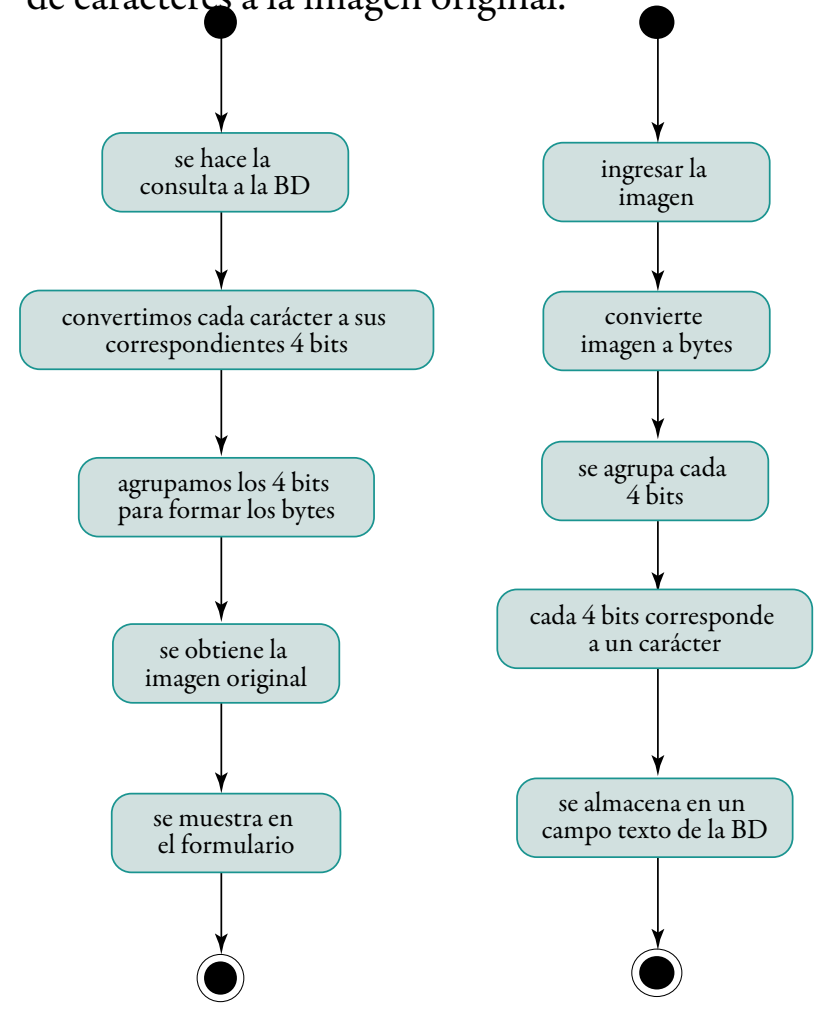

Figura 3.

El diagrama de clases (ver Figura 4) explica lo relacionado al componente:

El diagrama de colaboración (ver Figura 5) nos muestra los pasos a seguir cuando se ingresa una imagen a la aplicación.

El diagrama de secuencia (ver Figura 6) muestra paso a paso lo que realiza el componente cuando un usuario ingresa una imagen a la aplicación.

\section{RESULTADOS}

Los resultados de la investigación han sido satisfactorios, logrando reducir el peso de las imágenes mayores a $100 \mathrm{~KB}$ en un buen porcentaje. Esto se grafica claramente en la Figura 7. 


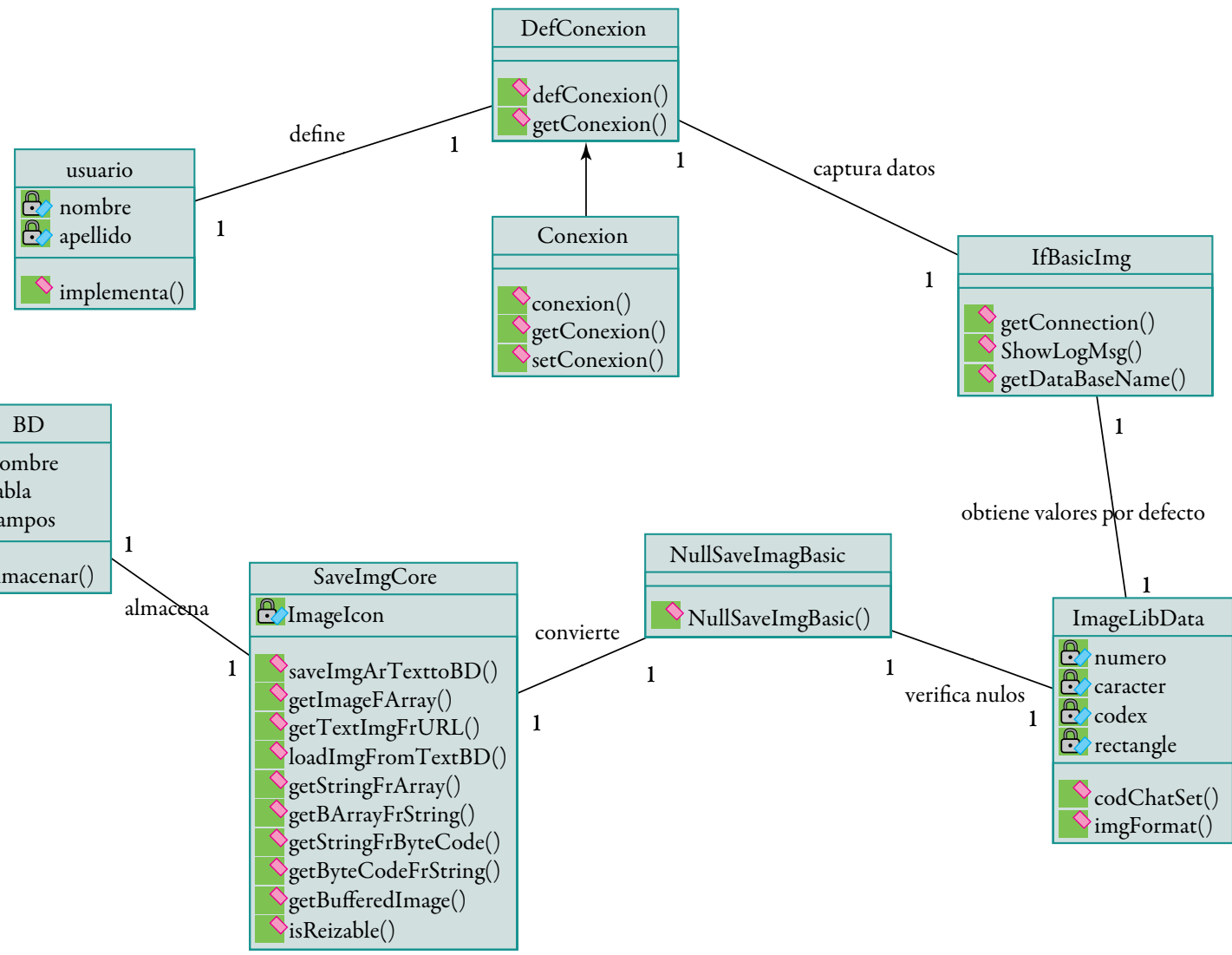

Figura 4

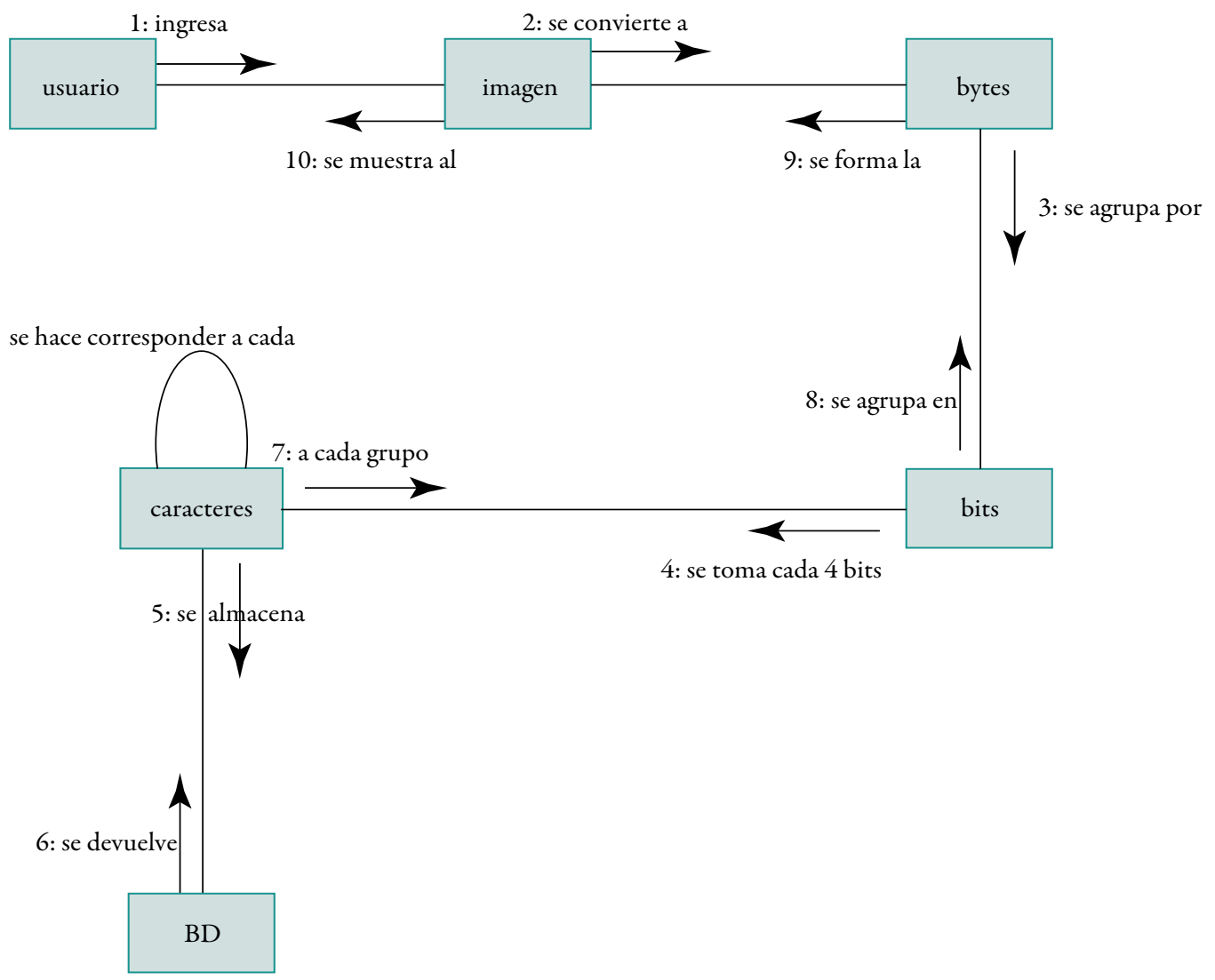

Figura 5 


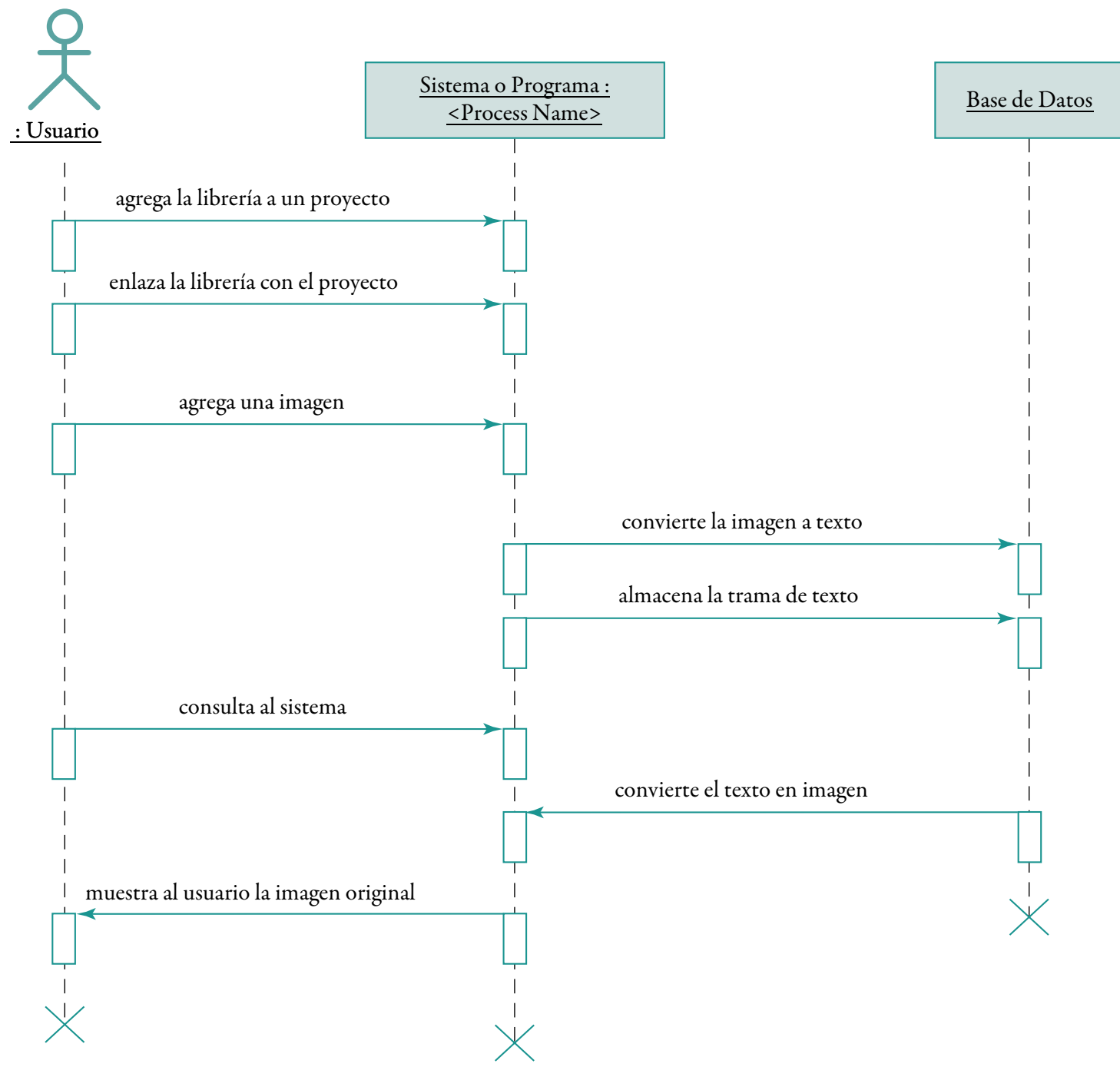

Figura 6

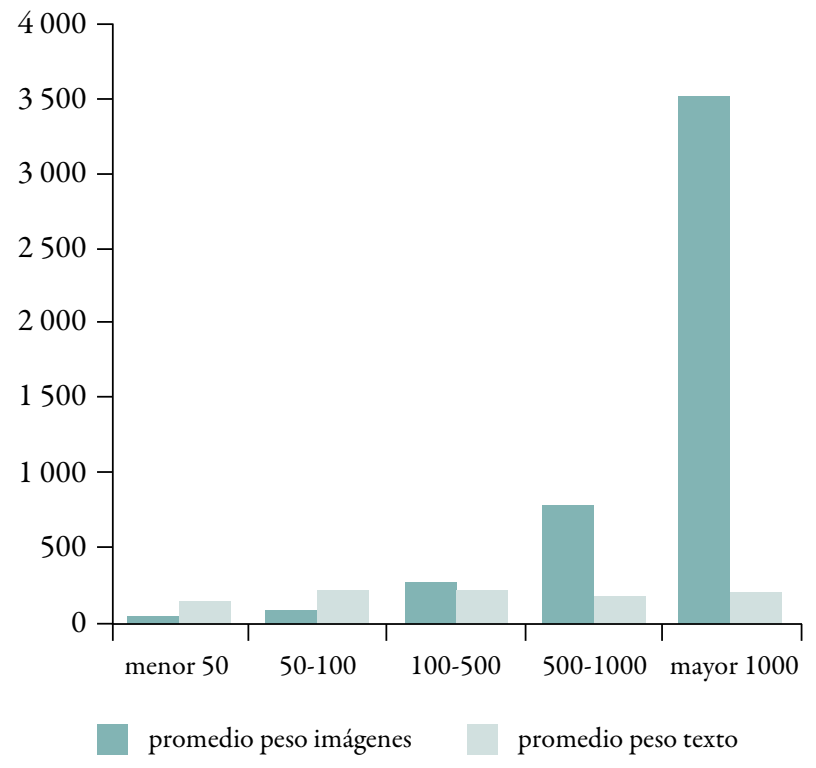

Figura 7

\section{CONCLUSIONES}

- Se ha logrado establecer los criterios para la elaboración del componente con base en las variables propuestas.

- Se ha logrado especificar los requisitos del componente.

- Se analizó y diseñó el componente basado en los requisitos antes mencionados.

- Se puede construir el componente a partir del prototipo presentado en el análisis y diseño.

- Se probó el componente, dentro de una 
aplicación, obteniendo buenos resultados en las pruebas realizadas.

- Se verificó la calidad de las imágenes convertidas, comparándolas con la imagen original en la aplicación.

- Se redujo el peso de las imágenes al convertirlas en texto para su almacenamiento en la BD.

- Se realizó el algoritmo capaz de convertir las imágenes a un conjunto de caracteres sobre la base de sus bytes.

\section{TRABAJOS FUTUROS}

- Primero: Probar el componente con otras bases de datos, para ver su flexibilidad.

- Segundo: Probar el componente con los demás formatos de imágenes que existen.

- Tercero: Implementar otro componente basado en el ya hecho, pero teniendo en cuenta el tipo de imágenes vectoriales, para la obtención de una mejor calidad en dichas imágenes.

\section{REFERENCIAS BIBLIOGRÁFICAS}

1. Gavin Powell. Beginning Database Design. Ed. Wiley Publishing, Inc. 2006

2. Steve Fogel. "Oracle Database Express Edition”. Oracle ${ }^{\oplus}$ Database Express. Edition 2 Day DBA 10g Release 2 (10.2)

3. Steve Fogel. "Oracle Database Express Edition 2 Day Developer Guide" $10 \mathrm{~g}$ Release 2 (10.2)

4. Mario Tamayo Tamayo. El Proceso de la
Investigación Cientifica. $4^{a}$ Edición. Noriega Editores

5. Ministerio de Administraciones Públicas. Metodología Métrica Versión 3.

6. "Tutorial de Digitalización de Imágenes". http://www.library.cornell.edu/preservation/ tutorial-spanish/intro/intro-04.html

7. "Licencia de documentación libre de GN. Base de Datos", en: http://es.wikipedia.org/ wiki/Base_de_datos

8. Lorena Arranz. "Imágenes Vectoriales y Mapa de Bits. Instituto de Tecnologías EducativasGobierno de España”, en: http://observatorio. cnice.mec.es/modules.php?op=modload\&na $m e=$ Newséfile $=$ articleきsid $=293$

9. "Imagen Vectorial". http://es.wikipedia.org/ wiki/Gr\%C3\%Alfico_vectorial

10. "Imagen Digital". http://es.wikipedia.org/ wiki/Imagen_digital

11. "Pixel". http://es.wikipedia.org/wiki/ P\%C3\%ADxel

12. Carlos Chávez García. "Qué son las Bases de Datos", en: http://www.maestrosdelweb.com/ principiantes/\%C2\%BFque-son-las-bases-dedatos/

13. Instituto Geográfico Agustín Codazzi. "Sistema de Gestión de Bases de Datos", en: http://www.igac.gov. co:8080/igac_web/UserFiles/File/ciaf/ TutorialSIG_2005_26_02/paginas/ctr_ sistemasdegestiondebasededatos.htm

14. Sara Álvarez. "Arquitectura de la Base de Datos", en: http://www.desarrolloweb.com/ articulos/arquitectura-base-de-datos.html

15. ALEGSA. "Definición BMP", en: bttp:/ www.alegsa.com.ar/Dic/bmp.php 